\title{
INTERNET OF THINGS IN MARKETING: OPPORTUNITIES AND SECURITY ISSUES
}

\author{
Irakli ABASHIDZE \\ Shota Rustaveli State University \\ Marcin DĄBROWSKI \\ Silesian University of Technology
}

\begin{abstract}
:
Internet of Things (IoT) affects different areas of human activities: everyday life of ordinary citizens, work style of marketing teams, factories and even entire cities. Large companies try to implement the technology in their marketing strategy that reshapes not only communication style and product promotion but consumers' expectations, perceptions and requirements towards companies. loT is expected to become a huge network that will encompass not only smart devices but significantly influence humans' behavior, in this particular case - decision making style in different phases of purchase process. Therefore, the need for comprehensive scientific research is necessary. The issue needs to be reviewed from various points of view, such as opportunities, advantages, disadvantages, legal and technical considerations. The paper is an attempt to review different aspects of using Internet of Things for marketing purposes, identify some of the major problems and present possible ways of solution.
\end{abstract}

Key words: internet marketing, Internet of Things, advertising

\section{INTRODUCTION}

Internet of Things (IoT), which was first popularized as a concept in 1999, simply can be defined as a network of interconnected devices [12]. The range of devices is very broad as the word "device" may refer to computers, smartphones, vehicles, house equipment, manufacturing devices, medical implants, even entire buildings and the list can be much longer (Fig. 1).

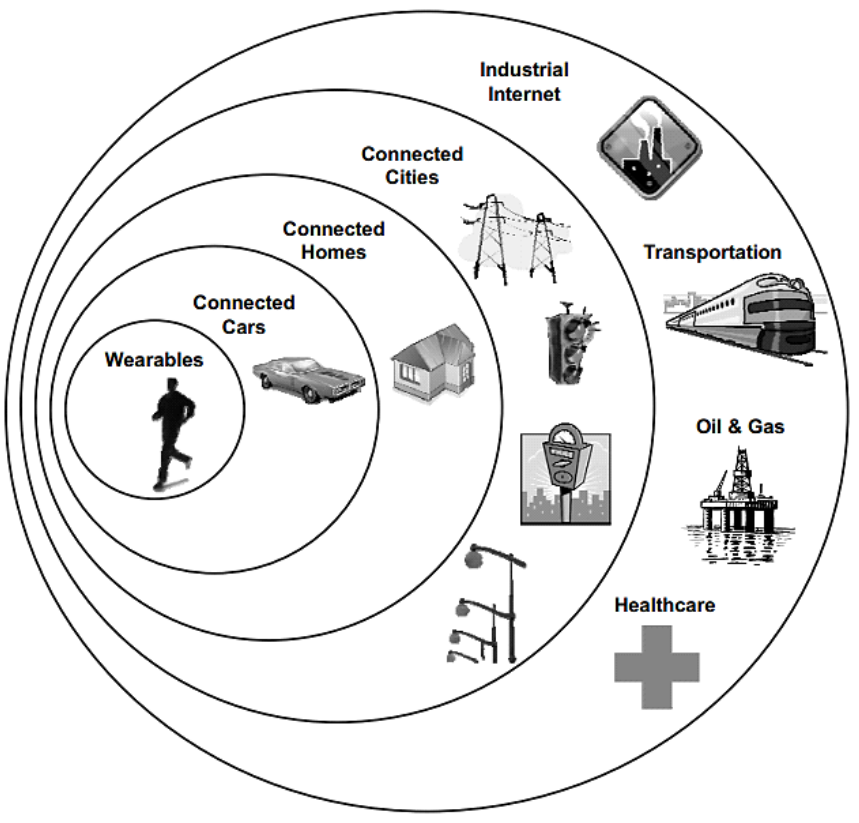

Fig. 1 Internet of Things in various areas of activities Source: [4].
The objects collect and exchange data thereby allowing their owners to gain a wide variety of benefits. For example, by using loT technologies it is possible to remotely monitor blood pressure and heart rate; or it is possible to integrate energy consuming devices into one loT-powered system and increase efficiency of power consumption; or if we consider a case from marketing, it is possible to have a smart refrigerator that is able to monitor producr supply in it and suggest its owner to buy something when there is a shortage of products, or even make it for its owner. It is estimated by the research that the number of loT devices will reach up to 50 billion by 2020 [1]. It means that, on average, there will be 6.5 loT device per person in 2020 . Although, if we take into consideration that the number of internet users is much less than the world population, the number of devices per internet user will be even higher. The areas where loT technologies can be used is, probably, limitless: transportation, infrastructure management, environmental monitoring, media, home automation and marketing, of course.

Internet of Things can be also considered as a tool for promotion products and services, communication with consumers, collecting marketing data, targeting audiences and for a variety of other marketing purposes. Its opportunities in marketing are, probably, boundless. Although, many marketers and scholars consider it as a future of marketing rather than something that is already actively in use today. Internet of Things and internet marketing as a whole is an area where practical development is way more advanced than its theoretical basis. Therefore, the need for scientific research increases as it can contain many risks and hazards. 
The more comprehensive the scientific research the more opportunities for elimination risks and threats. As for risks and threats, whilst discussing Internet of Things and its opportunities, security and privacy is one of the most actively mentioned issues. As highlighted in a report [9] by a group of researchers working specifically in the area of IoT, there are three major challenges that need to be adequately reacted by all stakeholders in loT network: consent on data transfer from users, freedom of choice and anonymity. This issue is especially problematic when it comes to collecting personal data of consumers by marketers for commercial purposes.

IoT can become a tool that will be able to improve all aspects of marketing. Moreover, its technical capabilities will allow marketers to plan and conduct marketing campaigns in a completely innovative manner. However, there are several aspects that should be emphasized. First of all, convenience for consumers. This is something that determines consumer behavior in favor of a company and its marketing team. As Neil Patel (analytics expert in digital marketing and co-founder of analytics company KISSmetrics) stresses in his article [8]: "IoT takes convenience to a whole new level". The methods of offering a product and purchasing are being changed. In this process race for obtaining consumer loyalty and competitiveness increases on the maximum level. Mere offers of products and services will no longer satisfy consumers. Instead, they will prefer those offers that will contain some additional features. Of course, this method has been used in marketing for a long time but the approaches and creativeness will be completely different. IoT technologies give marketers an opportunity to identify consumer needs, wants and demands. Such differentiation of prerequisites of consumer behavior is provided by Philip Kotler in his book "Marketing management". As the author explains, "needs" encompass the main human requirements; "Wants" refer to specific products entailed by needs; "Demands" are wants for more specific products backed by an ability to pay [5]. All this aspects of consumer requirements will become easier to identify by IoT's technical abilities. Therefore, the level of competition between companies will grow immensely and those who will manage to adequately respond to new requirements, will obtain consumer loyalty.

\section{IOT AS AN INNOVATIVE APPROACH IN MARKETING}

While using IOT in marketing the manner and methods of communication with consumers becomes personal like never before. Targeting a desired audience and preciseness of segmentation also reaches new levels. It can be considered even as a whole new type of direct marketing. Companies will be able to offer a product or service to each separate consumer. This feature can become a premise for more sophisticated personalized marketing. Besides, advertising becomes less irritating inasmuch as a consumer expresses willingness to get information about products and services. This is another proof that the future of interruption marketing becomes opaque and permission marketing becomes more and more effective. IoT technologies can facilitate this trend.

When it comes to communication, IoT technologies open a lot of new possibilities for marketers. For example, integration of loT devices with social media (Fig. 2).

Receiving feedbacks on products in social media is already widely used by companies. It affects formation of societal interest and influences opinions of each social media user. Finally, such interaction may influence a product and its features. When loT technologies and social media merge, a virtual space will be created where a company and a user will have closer connection. Besides exchange of verbal information, possibilities of ordering a product from a consumer and modifying it by a company according to consumer requirements will be possible. Needless to say, loT will become an integral part of integrated marketing communications and change the way companies communicate with their existing or potential consumers. However, it doesn't mean that "traditional" methods will fade away.

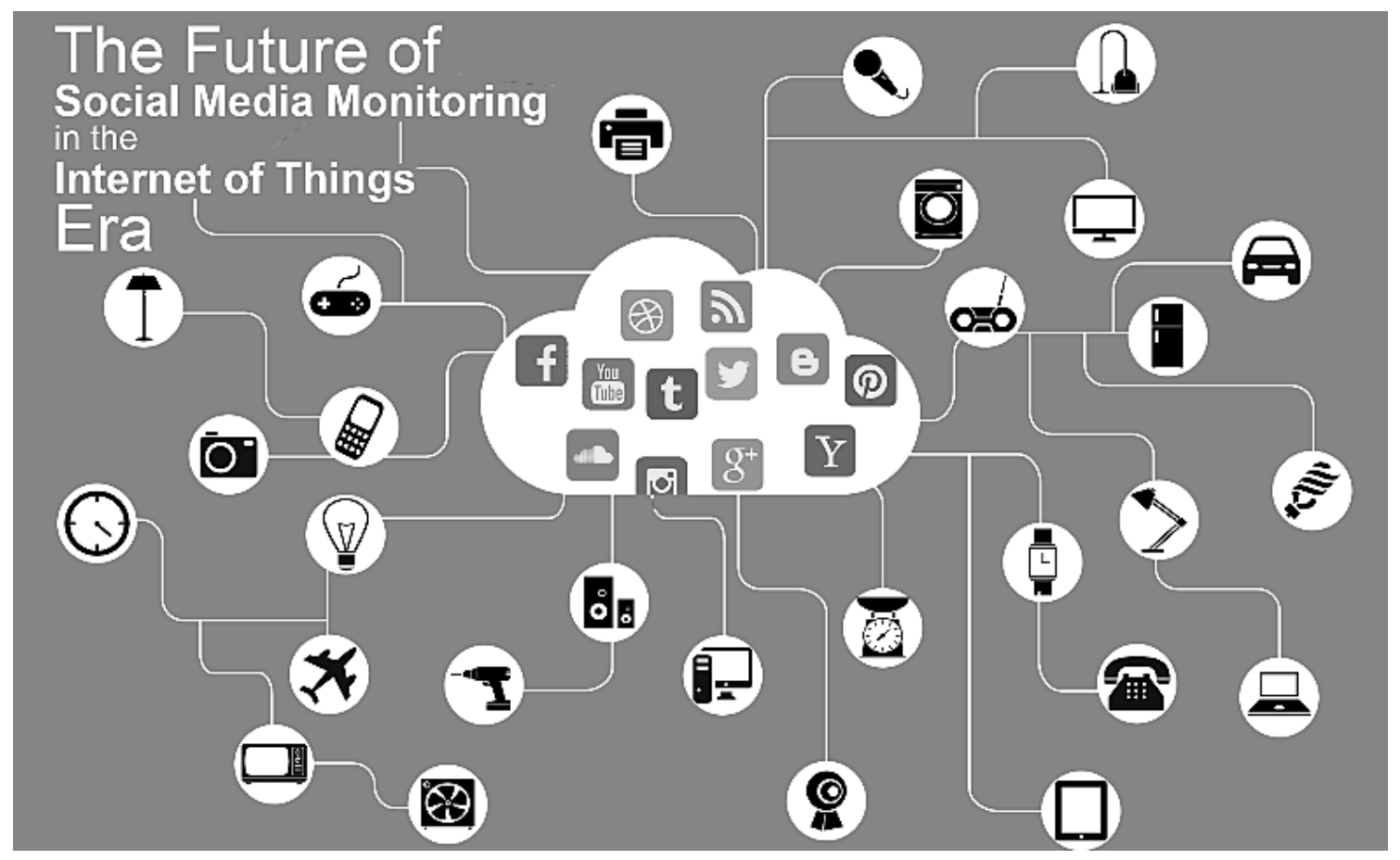

Fig. 2 Integration of loT devices with social media

Source: [10]. 
Furthermore, they may experience more sophistication and only those companies will retain market share that will manage to use all the channels of communications accordingly and loT technologies will be one of the most important of them.

Collecting marketing data is one of the primary goals for a marketer. The more precise and comprehensive consumer data, the more opportunities to target desired audience, increase conversion rate, raise brand awareness and so forth. IoT technologies give opportunities to collect consumer data in limitless amount and quality. As for the types of the information, it can be age, gender, interests, social status, income, tastes, purchase and other types of habits, location and many more. Segmentation opportunities become more powerful and precise. Since interaction between a consumer, loT devices and physical world can be rather intense, marketers are able to track even the most detailed traits of consumer behavior. Vast majority of consumers already use mobile devices while making decisions in shops and considerable number of these consumers are ready to make touchless or one-click payment from devices [6]. Consumers express increasingly more readiness to use mobile and wearable devices while shopping. This fact is especially interesting for retailers, as they are able to collect data about each single purchase, type of a consumer (age, gender, etc.) and build statistical database that will later help a marketing team improve product, delivery method, advertising strategy, targeting strategy and many more [2].

Special attention should be paid on the ability of loT technologies to track consumer locations. Since one of the components of $4 \mathrm{P}$ (product, price, place, promotion) is "place", it is of utmost importance to know where and when are consumers during a particular period of time. The remaining three components can be determined by a company but a marketing team should know where to deliver a product. These components depend on one another and absence of even one of them can cause problems in the whole marketing chain. Therefore, companies try to collect all the data from all the sources, analyze them, make consumer profile and use this information for commercial purposes. Of course, many consumers are concerned about the fact that their location can be tracked by someone but there is significant number of consumers who are ready to give this information to companies in exchange of some benefit or discount. This circumstance should become the most attractive opportunity for marketers to persuade consumers in sharing their personal data.

One of the most outstanding examples of using loT technologies for all aspects of marketing, doubtlessly, is Nike+. This is a very successful example of connecting a consumer, mobile device, wearable device and internet. All these already exist today and has great number of users. By integrating different components in one mobile application, Nike managed to offer users a variety of services. The main function of the application for its users is to track a person's jogging routes, measure speed, count burned calories. The data is stored and a user is able to monitor progression. Besides, the application allows a user to share results in social media. Furthermore, the application itself is a sort of social network where users are able to add each other in friend lists, challenge each other and view results. As for the commercial purposes, the application allows users to purchase sport clothes by online shopping. Some running shoes come with special sensors inside that can track a user's run and transfer data to the device [7]. First of all, that is worth mentioning is that this application helps Nike's marketing team collect priceless data about consumers, such as their age, gender, location, exercising habits, routes, email addresses etc. Such precise information, probably, would not be possible to collect by a market research. What is the most important, this information costs nothing for Nike, whereas a market research can be rather expensive. Another important aspect is that the application is integrated with social media that allows the company to have very close and intense communication with its consumers; and finally, the application brings commercial benefit by selling products online using the application itself. As a result of combination of all its components, the application is an example of excellent use of loT technologies.

\section{SECURITY ISSUES AS THE MAIN CHALLENGE OF IOT IN MARKETING}

Gathering consumer data is a very attractive feature of IoT from point of view of marketers but it raises controversies regarding security and privacy of consumers. Data retrieved using loT technologies can be very detailed and contain information exposed to abuse in various ways. The network of loT will be so big that it will be impossible to completely eliminate all the risks and threats. The most difficult task in this process is that the sources of personal information in case of loT is, probably, countless and encompass not only computers and mobile devices but any other types of wearables, cars, house equipment, medical implants etc. Behavior of users is tracked everywhere and on a regular basis.

There are significant differences in how traditional internet technologies and IoT technologies are managed in terms of transferring information and making decisions. For example, in case of data entry, web technologies and users themselves are active, whereas in case of loT, users are passive and devices are sources of data; In case of data sharing, web technologies allow making it with other providers, unlike loT where data is shared with other devices; In web space users take actions online, whilst in loT actions are taken in physical world; As for making decisions, often devices in loT network do it instead of their users [13]. Such dependence on devices in physical world, apart from others, creates a risk of malfunction of devices that can negatively affect their private life, damage financial conditions or even health. As a result, consequences can be extremely negative and possibly sometimes fatal. While using loT technologies, consumers unconsciously trust providers of services, in this case marketing teams and provide them with great amount of private information.

When it comes to threats, of course, hacking is one of the most frequently mentioned cases. It is even more dangerous in case of loT devices because targets of hackers are not only databases but physical objects that in many cases can damage human health. The damage can be not only leaked personal data but it can create danger for human lives. For example, cars in loT network are vulnerable to hacker attack. If we consider the issue from marketing point of view, hacking a company's database containing consumers' personal information can be harmful not only for consumers as victims of attack, but also for a company that can experience big amount of financial loss, damage of reputation, crisis in public relations and even bankruptcy.

Another one concern on using loT technologies in marketing is of legal character. If personal data is leaked or illegally transferred to a third party, consumers may sue a 
company demanding moral and monetary compensation. Such cases may cause huge damage for a company, depending on the amount, type of data and number of consumers. Of course, laws forbidding transfer of personal information and illegal entry in databases already exist but legislation must correspond new challenges entailed specifically by implementation of loT technologies. For example, data protection regulation in the European Union known as "the right to be forgotten" states that information about an individual must be deleted after a certain period of time [3]. However, it can be a very difficult task to fulfill inasmuch as in most cases information is stored in cloud-based spaces. Copying and spreading digital information is a matter of elementary technical skills. Therefore, "the right to be forgotten" regulation may turn out to be ineffective. Eventually, the problem of storing and transferring personal data still remains as one of the main concerns in loT-based marketing solutions [11].

\section{POSSIBLE WAYS OF UTILIZING IOT AS AN EFFECTIVE AND SAFE TOOL IN MARKETING}

While discussing possible risks and ways of solution, several aspects should be emphasized. Each of them should be approached individually and by different stakeholders. Nonetheless, there is no absolute guarantee that all the possible difficulties will be overcome as development of the technology itself is accompanied by appearing different threats and more advanced methods of abusing it. However, the following actions can be undertaken in order to minimize damage in various directions:

In order to avoid any sort of misunderstanding and risks, marketing teams should make aware consumers that their personal data is stored and used for commercial purposes. Consent for data transfer must be obligatory. The level of transparency must be as high as possible. Such approach will allow companies to eliminate or, at least, minimize possible dissatisfaction and losing current or potential consumers. Creating a team with qualified specialists who will focus specifically on protecting a company's digital databases also can be regarded as one of the solutions. Although, not all companies can afford this level of security.

Comprehensive scientific research is vitally important. Thorough studies must be conducted in order to eliminate threats. The research process must be multilateral and comprise not only technical aspects but the methods of how companies will offer their products and manners of communication. World scale companies that operate in technological areas should play the main role in this process as they possess not only financial resources needed for wide scale scientific studies but also rich human resources for conducting valuable research in this area. These companies should consider this process within the framework of social responsibility policy, not only as a basis of their future commercial success.

The role of governments in process of creating legal basis is also very important. Strict regulations in cases of abuse of personal data will significantly prevent criminals and hackers from abusing personal data. Although, the level of competence of the governments in various countries in this field is very different. Yet, internet and loT devices is spreading all over the world. Therefore, the level of security in different countries may not be equally high. In order to raise awareness and competence, various international conferences and workshops should be conducted both on governmental and non-governmental levels.

\section{CONCLUSION}

Despite all concerns and risks, development of loT technologies and its implementation in marketing is inevitable. Therefore, all the stakeholders in this process should play their own role in its safer, legal and beneficial operation. Marketers need to elaborate detailed policy on how and for what specific purposes will consumer data be used and make it transparent. Besides, they should create marketing plans specifically for loT because the methods and approaches in communication with consumers will be different from traditional internet marketing. It will allow companies to develop their products and services properly. Besides, companies must assure their consumers that their personal data is stored securely and protected from third parties. This is very important in obtaining trust among consumers. On the other hand, consumers should be aware about all the details of how and why their personal data is used by marketers. The level of their awareness may not be equally high for everyone but over time this problem will be solved based on their own experience.

In order to summarize the topic, several aspects should be pointed out; First of all, loT technologies give completely new and powerful opportunities to marketers. Mostly it concerns the ways how consumer data is collected and also the ways of communication with consumers. Besides, awareness on its security should be higher in order to avoid possible risks and threats. Such goal can be achieved by thorough scientific studies and strict regulations on legal level. Finally, similar to previous scientific and technical development, some challenges and sometimes even major problems may occur. However, gradually the process will find its right path and loT technologies will become a powerful tool for companies in their marketing strategies.

The author would like to express his gratitude to professor Jan Kaźmierczak and doctor Marcin Dąrowski for their supervision and assistance while creating this paper. This paper is the result of the project, called:

Production engineering methods and tools for development of smart specializations (No. 13/030/BK_16/0024).

\section{REFERENCES}

[1] D. Evans. (2011) The internet of things. How the next evolution of the internet is changing everything [Online]. Available: http://www.cisco.com/c/dam/ en_us/about/ac79/docs/innov/ IoT_IBSG_0411FINAL.pdf

[2] J. Gregory. The Internet of Things: Revolutionizing the Retail Industry [Online]. Available: https:// www.accenture.com/_acnmedia/Accenture/ Conversion-Assets/DotCom/Documents/Global/PDF/ Dualpub_14/Accenture-The-Internet-Of-Things.pdf

[3] M. Henze, L. Hermerschmidt, D. Kerpen et al. „A comprehensive approach to privacy in the cloud-based Internet of Things", in Future Generation Computer Systems, vol. 56, 2016, pp. 701-718.

[4] S. Jankowski, J. Covello, H. Bellini et al. (2014) The Internet of Things: Making sense of the next mega-trend [Online]. Available: http://www.goldmansachs.com/ our-thinking/outlook/internet-of-things/iot-report.pdf

[5] P. Kotler. „Needs, wants and demands”, in Marketing management, millennium edition, P. Kotler, New Jersey: Prentice-Hall Inc., 2001. 
[6] S. Kramer. (2015) Optimizing Internet of Things data tracking in-store [Online]. Available: http:// www.ibmbigdatahub.com/blog/optimizing-internetthings-data-tracking-store

[7] R. Macmanus. (2010) Top ten internet of things developments of 2010 [Online]. Available: http:// readwrite.com/2010/12/15/ top_10_internet_of_things_developments_of_2010

[8] N. Patel. (2015) How the Internet of Things is changing online marketing [Online]. Available: http:// www.forbes.com/sites/neilpatel/2015/12/10/how-the -internet-of-things-is-changing-online-marketing/ \#26d67d21456e

[9] C. Perera, R. Ranjan, L. Wang et al. (2015) Privacy of Big Data in the Internet of Things Era [Online]. Available: http://arxiv.org/ftp/arxiv papers/1412/1412.8339.pdf

[10] The Future of Social Media Monitoring in the Internet of Things Era [Online]. Available: http:// www.mentionlytics.com/blog/future-social-mediamonitoring-internet-things-iot/

[11] R. Davies. (2015) The Internet of Things, Opportunities and challenges [Online]. Available: http:// www.europarl.europa.eu/RegData/etudes/ BRIE/2015/557012/EPRS_BRI(2015)557012_EN.pdf

[12] O. Vermesan and P. Friess. (2014) Internet of Things from research and innovation to market deployment [Online]. Available: http://www.internet-of-thingsresearch.eu/pdf/loT-From\%20Research\%20and\% 20Innovation\%20to\%20Market\% 20Deployment_IERC_Cluster_eBook_978-87-9310295-8_P.pdf

[13] B. Weinberg, G. Milne, Y. Andonova and F. Hajjat. „Internet of Things: convenience vs. privacy and security", in Business Horizons, vol. 58(6), 2015, pp. 615624.

Irakli Abashidze, M.Sc

Shota Rustaveli State University, Batumi

Chavchavadze 78/88, apt. 182; Batumi 6009, GEORGIA

e-mail: irakliab@gmail.com

dr inż. Marcin Dąbrowski

Silesian University of Technology, Faculty of Organization and Management Institute of Production Engineering

ul. Roosevelt 26-28, 41-800, Zabrze, POLAND

e-mail: marcin.dabrowski@polsl.pl 